\title{
Significance of the epidermal growth factor receptor mutation status and differences among molecular subgroups in surgically resected lung microinvasive adenocarcinoma
}

\author{
MING LI ${ }^{1 *}$, CHUANYING LI ${ }^{1 *}$, LI KE ${ }^{2}$, MALI ZHAN $^{1}$ and MIN CHENG ${ }^{3}$ \\ Departments of ${ }^{1}$ Pathology and ${ }^{2}$ Thoracic Surgery; ${ }^{3}$ The Gerontology Institute of Anhui Province, Anhui Provincial Hospital, \\ The First Affiliated Hospital of University of Science and Technology of China, Hefei, Anhui 230001, P.R. China
}

Received December 26, 2017; Accepted August 24, 2018

DOI: $10.3892 / \mathrm{ol} .2018 .9539$

\begin{abstract}
Lung microinvasive adenocarcinoma (MIA) is a newly-defined subtype of early stage non-small cell lung cancer (NSCLC). However, its epidermal growth factor receptor (EGFR) mutation status and clinical significance remain unclear. The present study aimed to determine EGFR mutation characteristics and identify their significance in patients with resected lung MIA. The present study also analyzed clinicopathological differences between EGFR molecular subgroups defined as 19Del and L858R. The present study examined EGFR mutations in 79 consecutive lung MIA resection specimens and compared the differences in clinicopathological features between the EGFR wild-type and mutation groups, as well as between the 19Del and L858R subgroups. EGFR mutations were detected in $60(75.95 \%)$ tumors. The most common mutations were 19Del (28 cases; $35.44 \%$ ) and L858R (30 cases; 37.97\%). Two patients harbored rare mutations and one of them had a concomitant double mutation. EGFR mutations were significantly associated with microinvasion component, thyroid transcription factor 1 (TTF-1) expression, intratumoral fibrosis and inflammatory cell infiltration. Subgroup evaluation indicated that there was a significant association between 19Del and tumor size, maximum diameter of microinvasion, presence of intratumoral fibrosis and inflammatory cell infiltration. Similar associations were observed for the L858R subgroup, and L858R was associated with TTF-1 expression. In particular, 19Del occurred more frequently in MIA with a smaller size, with a smaller
\end{abstract}

Correspondence to: Dr Ming Li, Department of Pathology, Anhui Provincial Hospital, The First Affiliated Hospital of University of Science and Technology of China, 17 Lujiang Road, Hefei, Anhui 230001, P.R. China

E-mail: aylm123@163.com

${ }^{*}$ Contributed equally

Key words: epidermal growth factor receptor, mutation, non-small cell lung cancer, microinvasive adenocarcinoma, molecular subgroup microinvasive area, without TTF-1 expression, and lacking intratumoral fibrosis and inflammatory cell infiltration. By contrast, L858R was detected more frequently in MIA with entirely different tumor features. In conclusion, the results of the present study indicated that surgically resected MIA cases harboring different EGFR gene statuses exhibit distinct clinicopathological features. Significant differences in pathological features associated with the tumor microenvironment were identified in MIA with 19Del or L858R mutations. Therefore, the present study proposed that MIA should be classified into molecular subgroups based on EGFR mutation subtypes. The molecular sub-classification should be taken into account for prognostic evaluation and clinical management of MIA.

\section{Introduction}

Lung cancer is one of the most common types of cancer worldwide and it remains the leading cause of cancer-associated mortality among all human malignancies (1). In developing and developed countries, the morbidity and mortality rates of lung cancer have markedly increased, particularly in China (2). Non-small cell lung cancer (NSCLC) accounts for $80-85 \%$ of lung cancer cases according to the World Health Organization (WHO) classification (3). Over the past decade, the treatment strategy for NSCLC has changed significantly and the therapeutic efficacy has improved with the application of novel individualized therapy. This is based on specific molecular alterations that define biological characteristics of lung cancer and may be used to predict treatment response (4). The epidermal growth factor receptor (EGFR) gene is considered the most valuable driver oncogene in the clinical management of NSCLC. EGFR gene mutations are identifiable in $10-50 \%$ of later stage NSCLC cases and are frequently detected in female non-smoker Asian patients with adenocarcinoma (5-7). EGFR tyrosine kinase inhibitors (TKIs) have exhibited promising clinical efficacy for the treatment of advanced NSCLC harboring sensitive EGFR mutations (8). Phase III randomized trials have provided robust evidence that EGFR TKIs could be applied as first-line therapy for advanced NSCLC with particular EGFR mutations (9-12).

EGFR mutation detection is being established as a prerequisite for the tailored treatment of late stage NSCLC. The 
diagnosis of early-stage lung adenocarcinoma has increased and stage I lung adenocarcinoma is the most common type of lung cancer in China, including MIA (13). However, few studies have investigated the characteristics of EGFR mutation or its significance in lung MIA $(14,15)$. The present study described the EGFR mutation spectrum in surgically resected MIA specimens from Chinese patients and further evaluated the association between clinicopathological features and EGFR mutation status. Furthermore, the present study aimed to investigate the differences in clinicopathological parameters between the two most common EGFR mutation subtypes (deletion in exon 19 and point mutation in exon $21 \mathrm{~L} 858 \mathrm{R}$ ), and to analyze the clinical relevance of this.

\section{Materials and methods}

Ethics approval. The study protocol was approved by the Institutional Review Board of Anhui Provincial Hospital, The First Affiliated Hospital of University of Science and Technology of China (Anhui, China; reference no. 20160183). Written informed consent was obtained from all patients and all patients agreed to the use of tissue samples for EGFR mutation analysis. The present study was performed according to the approved guidelines and principles of good clinical practice.

Patients and samples. Between January 2015 and June 2017, 79 patients (32 male and 47 female; (median, 58; range 39-82 years of age) who underwent pulmonary resection for a small pulmonary nodule following low-dose computed tomography (LD-CT) examination, were enrolled at Anhui Provincial Hospital. Patients included in the present study met the following inclusion criteria: i) Pathologically-confirmed pulmonary microinvasive adenocarcinoma diagnosis, according to the WHO Classification of Lung Tumors (4th edition) (16), and ii) surgically resected specimens available for EGFR mutation detection. Patients were excluded from the present study if they had received chemotherapy, radiotherapy or other therapy prior to surgery.

All resected tissue samples were fixed in $10 \%$ neutral-buffered formalin for $24 \mathrm{~h}$ at room temperature and embedded in paraffin. Clinical and pathological data were collected from the medical records of each patient. Histological subtype and the maximum size of the microinvasion component were evaluated by 3 pathologists, (ML, MZ and CL) from the Department of Pathology, Anhui Provincial Hospital, The First Affiliated Hospital University of Science and Technology (Hefei, China), according to the new International Association for the Study of Lung Cancer/American Thoracic Society/European Respiratory Society adenocarcinoma classification and WHO criteria $(16,17)$. The patient demographic characteristics are summarized in Table I.

Immunohistochemical (IHC) analysis and TTF-1 scoring. IHC staining was performed according to a previously described method (18). In brief, 4- $\mu \mathrm{m}$ thick formalin-fixed, paraffin-embedded tissue sections were deparaffinized in xylene and rehydrated in gradient ethanol, which included 100,95 , and $85 \%$ ethanol. Tissue sections were treated with $3 \%$ hydrogen peroxide at room temperature for $10 \mathrm{~min}$ and washed with PBS ( $\mathrm{pH} 7.4)$, and antigens were retrieved at a high-temperature of $\sim 102^{\circ} \mathrm{C}$ and high-pressure for $2 \mathrm{~min}$ in citrate buffer (pH 6.0; cat. no. 14746; Santa Cruz; Santa Cruz Biotechnology, Inc., Dallas, TX, USA). The slides were subsequently washed with PBS ( $\mathrm{pH} 7.4)$ and blocked in 3\% bovine serum albumin (cat. no. 9998; Santa Cruz; Santa Cruz Biotechnology, Inc) at room temperature for $30 \mathrm{~min}$. A TTF-1 monoclonal antibody (dilution, 1:200; clone 8G7G3/1; cat. no. IS05630; Dako; Agilent Technologies, Inc., Santa Clara, CA, USA) was used as the primary antibody for TTF-1 detection. The slides were incubated with the primary antibody for $2 \mathrm{~h}$ at room temperature. The TTF-1 IHC staining was performed according to the manufacturer's protocol of the Envision Two-step Detection kit (cat. no. GK500705; Dako; Agilent Technologies, Inc.). The IHC slides were analyzed under a light microscope Olympus BX 51 (magnification, x200; Olympus Corporation, Tokyo, Japan). TTF-1 expression was indicated by nuclear staining.

Previous studies $(19,20)$ have performed TTF-1 expression scoring based on the staining intensity. The intensity was scored as follows: 0, no expression; 1, weak expression; 2, intermediate expression; or 3, strong expression. A sample was defined as negative for tumor cells with a score of $<2$ and positive for tumor cells with a score of $\geq 2$.

EGFR mutation analysis. Genomic DNA was isolated and purified from formalin-fixed paraffin-embedded tissues using a QIAamp DNA FFPE Tissue kit (cat. no. 56404; Qiagen $\mathrm{GmbH}$, Hilden, Germany), according to the manufacturer's protocol. Macrodissection of materials from tissue sections was performed if necessary for specimens containing insufficient tumor components (the proportion of tumor cells was $<50 \%$ ). The extracted DNA purity and concentration were evaluated by a NanoDrop 2000 ultraviolet spectrophotometer (NanoDrop Technologies; Thermo Fisher Scientific, Inc., Waltham, MA, USA). EGFR mutation status was detected using Human EGFR Gene Mutation Detection kit (cat. no. 20143402001; ADx-ARMS; Amoy Diagnostics Co., Ltd., Amoy, Fujian, China), according to the manufacturer's protocol for the amplification refractory mutation system quantitative polymerase chain reaction (PCR). A total of 29 mutations were detected in the present study, including G719A, G719S, G719C, T790M, L858R, L861Q and S768I, three types of insertions in exon 20, and 19 types of deletions in exon 19. Positive and negative controls were set in each experiment. The positive controls were the plasmids containing mutated EGFR gene sequences and negative control were the plasmids containing the wild-type EGFR gene sequences. An external control was used for each sample to guarantee the loading of sufficient DNA template and an internal control was used in each reaction tube to exclude the presence of PCR inhibitors.

Statistical analysis. Statistical analysis was performed using SPSS software for Windows (version 13.0; SPSS, Inc., Chicago, IL, USA). The association between various clinicopathological parameters and EGFR mutation status was evaluated using the $\chi^{2}$ and Fisher's exact tests, as appropriate. Subgroup analysis aimed to investigate differences in EGFR gene status. All tests were two-sided and $\mathrm{P}<0.05$ was considered to indicate a statistically significant difference. 
Table I. Demographic characteristics of 79 Chinese patients with lung microinvasion adenocarcinoma.

\begin{tabular}{lcc}
\hline Factor & $\mathrm{n}$ & Proportion, $\%$ \\
\hline Total cases & 79 & \\
Age & & \\
$\leq 50$ & 16 & 20.25 \\
$51-60$ & 31 & 39.24 \\
$61-70$ & 21 & 26.58 \\
$>70$ & 11 & 13.92 \\
Sex & & \\
Male & 32 & 40.51 \\
Female & 47 & 59.49 \\
Smoking status & & \\
Never smoked & 71 & 89.87 \\
Smoker & 8 & 10.13 \\
Tumor number & & 82.28 \\
Single & 65 & 17.72 \\
Multiple & 14 & \\
Tumor site & & 35.44 \\
Left & 28 & 62.03 \\
Right & 49 & 2.53 \\
Bilateral & 2 & \\
\hline
\end{tabular}

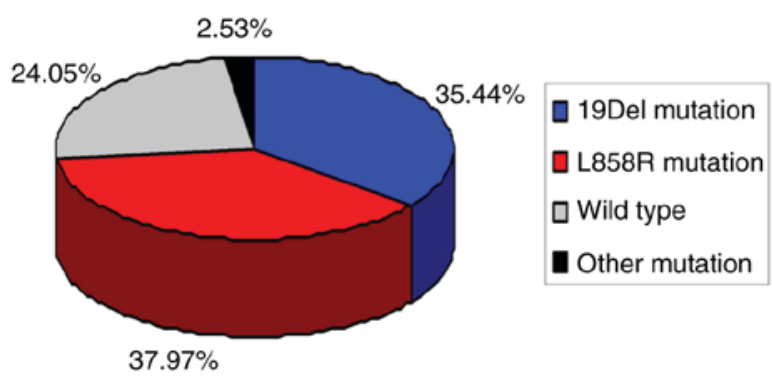

Figure 1. Mutation spectrum of the epidermal growth factor receptor gene in 79 patients with lung microinvasion adenocarcinoma.

\section{Results}

Descriptive characteristics of patients. A total of 79 patients with lung MIA were included in the present study and the demographic characteristics of these patients are summarized in Table I. All pathological diagnoses were determined by three professional pulmonary pathologists according to the criteria of the WHO/IASLC Histological Classification of Lung and Pleural Tumors. The median age at diagnosis was 58 years (range, $39-82$ years). There were $32(40.51 \%)$ male and 47 female $(59.49 \%)$ patients. A total of $8(10.12 \%)$ of the enrolled patients were smokers and $71(89.87 \%)$ had never smoked. With respect to the number of pulmonary tumors, $65(82.28 \%)$ patients had a single tumor and $14(17.72 \%)$ patients had multiple tumors. Tumors of 28 (35.44\%) cases were located in the left lung, $49(62.03 \%)$ cases in right lung and $2(2.53 \%)$ cases had bilateral tumors. Of all 79 patients included in the present study, MIA occurred more frequently in females, patients who had never smoked, patients aged 51-60 years and patients with a single tumor located in the right lung (Table I).

An EGFR mutation was identified in $60 / 79$ patients with MIA, with a $75.95 \%$ mutation rate. A total of 28 cases $(35.44 \%)$ had a deletion in exon 19 (19Del), 30 cases (37.97\%) had a point mutation in exon 21 (L858R) and 19 wild-type EGFR gene cases $(24.05 \%)$ were identified. The remaining 2 cases $(2.53 \%)$ harbored rare mutations, one of exon $18 \mathrm{G} 719 \mathrm{X}$, and the other was a concomitant double mutation of exon 18 G719X and exon 20 S768I. The mutation spectrum of EGFR in the 79 patients with MIA is described in Fig. 1.

Association between EGFR mutation status and clinicopathological characteristics. As presented in Table II, the distribution of EGFR mutations did not differ significantly according to sex, age at diagnosis, smoking status or tumor site/size/number in the 79 patients with MIA in the present study. The maximum diameter of microinvasion, percentage of lymphocytes in the peripheral blood and radiological appearance with or without ground glass opacity (GGO) were not associated with EGFR mutation. With respect to the histological subtype of microinvasion component according to the IASLC/ATS/ERS classification, the EGFR mutation occurred more frequently in lepidic and acinar predominant subtypes $(\mathrm{P}<0.01)$. However, the distribution of patients with EGFR was not significantly different between these two histological subtypes. In addition, EGFR mutations occurred more frequently in patients with intratumoral fibrosis and intratumoral inflammatory cell infiltration $(\mathrm{P}<0.01)$. On the other hand, the present study identified 63 cases $(79.75 \%$, defined as staining score $\geq 2$ ) with MIA that were TTF-1-positive and 16 cases $(20.25 \%$, defined as staining score $<2)$ that were negative (Fig. 2). EGFR mutations occurred more frequently in MIA patients with TTF-1 expression (Table II; P<0.01).

Comparison of clinicopathological characteristics among the EGFR mutation subtypes. As shown in Table III, subgroup analysis was conducted to analyze the association between the EGFR mutation subtype and clinicopathological parameters. The distribution of patients with 19Del and L858R in the present study cohort was similar with respect to sex, age at diagnosis, smoking status, tumor site and number, histological subtype of the microinvasive component, percentage of lymphocytes in the peripheral blood and radiological appearance with or without GGO. Nevertheless, there was a significant association between the 19Del mutation status and tumor size $(\mathrm{P}<0.01)$, diameter of tumor microinvasion $(\mathrm{P}<0.05)$, presence of intratumoral fibrosis $(\mathrm{P}<0.05)$ and inflammatory cell infiltration $(\mathrm{P}<0.01)$. There was a significant association between the L858R mutation and the aforementioned features. Furthermore, the expression status of TTF-1 protein was significantly associated with the L858R mutation status $(\mathrm{P}<0.05)$, but not with the 19Del mutation (Table III).

As demonstrated in Fig. 3 and Table IV, the present study also demonstrated that 19Del occurred more frequently in patients with MIA exhibiting small tumor size $(\mathrm{P}=0.004)$ and smaller diameter of microinvasive area $(\mathrm{P}=0.005)$. 19Del was also observed more frequently in patients without intratumoral fibrosis $(\mathrm{P}=0.000)$, inflammatory cell infiltration 
Table II. Association between the epidermal growth factor receptor mutation status and clinicopathological features.

\begin{tabular}{|c|c|c|c|}
\hline Factor & $\mathrm{n}$ & Mutation (\%) & P-value \\
\hline Total cases & 79 & $60(75.95)$ & \\
\hline Age & & & 0.303 \\
\hline$\leq 50$ & 16 & $13(81.25)$ & \\
\hline $51-60$ & 31 & $26(83.87)$ & \\
\hline $61-70$ & 21 & $13(61.90)$ & \\
\hline$>70$ & 11 & $8(72.73)$ & \\
\hline Sex & & & 0.871 \\
\hline Male & 32 & $24(75.00)$ & \\
\hline Female & 47 & $36(76.59)$ & \\
\hline Smoking status & & & 0.348 \\
\hline Never smoked & 71 & $55(77.46)$ & \\
\hline Smoker & 8 & $5(62.50)$ & \\
\hline Tumor number & & & 0.260 \\
\hline Single & 65 & $51(78.46)$ & \\
\hline Multiple & 14 & $9(64.28)$ & \\
\hline Tumor site & & & 0.495 \\
\hline Left & 28 & $20(71.43)$ & \\
\hline Right & 49 & $39(79.59)$ & \\
\hline Bilateral & 2 & $1(50.00)$ & \\
\hline Tumor size, $\mathrm{cm}$ & & & 0.301 \\
\hline$\leq 1$ & 46 & $33(71.74)$ & \\
\hline$>1, \leq 2$ & 33 & $27(81.82)$ & \\
\hline Presence of GGO & & & 0.660 \\
\hline Yes & 73 & $55(75.34)$ & \\
\hline No & 6 & $5(83.33)$ & \\
\hline Maximum diameter of tumor microinvasion, $\mathrm{mm}$ & & & 0.133 \\
\hline$\leq 2$ & 34 & $23(67.65)$ & \\
\hline$>2, \leq 5$ & 45 & $37(82.22)$ & \\
\hline Histological subtype of microinvasion component & & & $0.001^{\mathrm{a}}$ \\
\hline Lepidic predominant & 43 & $33(76.74)$ & \\
\hline Acinar predominant & 32 & $27(84.38)$ & \\
\hline Other sub-type & 4 & $0(0.00)$ & \\
\hline Intratumoral fibrosis & & & $0.007^{\mathrm{a}}$ \\
\hline Presence & 46 & $40(86.96)$ & \\
\hline Absence & 33 & $20(60.61)$ & \\
\hline Intratumoral inflammatory cell infiltration & & & $0.007^{\mathrm{a}}$ \\
\hline Presence & 38 & $34(89.47)$ & \\
\hline Absence & 41 & $26(63.41)$ & \\
\hline Percentage of lymphocytes in peripheral blood & & & 0.134 \\
\hline$\leq 30$ & 19 & $12(63.16)$ & \\
\hline$>30$ & 60 & $48(80.00)$ & \\
\hline Expression of TTF-1 protein & & & $0.007^{\mathrm{a}}$ \\
\hline Positive & 63 & $52(82.54)$ & \\
\hline Negative & 16 & $8(50.00)$ & \\
\hline
\end{tabular}

${ }^{\text {aP }}<0.01$. GGO, ground glass opacity; TTF-1, thyroid transcription factor 1 ; other subtype, other histopathological subtypes, including papillary predominant, micropapillary predominant and solid pattern predominant, classified and recorded according to the new IASLC/ATS/ERS lung adenocarcinoma classification; median percentage of lymphocytes in peripheral blood was 30\%; therefore, all enrolled patients were divided into two subgroups. 

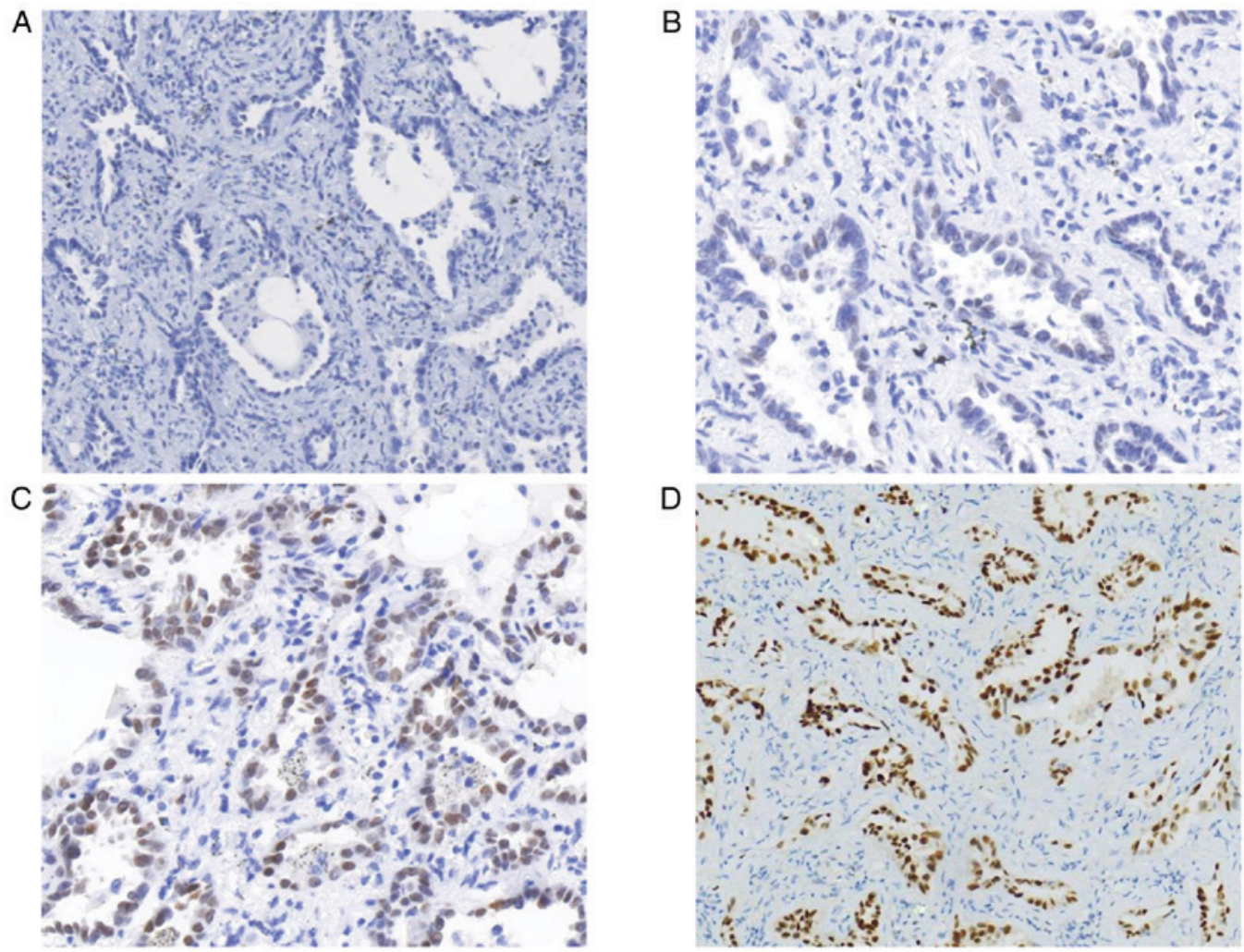

Figure 2. Representative examples of the immunohistochemical staining of TTF-1 in MIA. (A) Score 0, no expression of TTF-1 was detected in tumor cells; magnification, x100. (B) Score 1, weak expression of TTF-1 was detected in tumor cells; magnification, x200. (C) Score 2, intermediate expression of TTF-1 was detected in tumor cells; magnification, x200. (D) Score 3, high expression of TTF-1 was detected in tumor cells; magnification, x100. TTF-1, thyroid transcrsiption factor-1.

$(\mathrm{P}<0.001)$ and TTF-1 expression $(\mathrm{P}=0.033)$. By contrast, the subgroup analysis revealed that the L858R mutation was more frequently detected in patients with MIA with larger tumors $(\mathrm{P}<0.001)$, larger diameters of microinvasive area $(\mathrm{P}=0.005)$, intratumoral fibrosis $(\mathrm{P}=0.001)$ and inflammatory cell infiltration $(\mathrm{P}<0.001)$. Furthermore, significant differences were not observed between the 19Del and L858R subtypes with regard to other clinicopathological feature subgroups.

\section{Discussion}

The present study aimed to improve the understanding of the EGFR mutation features, and their clinicopathological relevance, in MIA. MIA is a newly defined subtype of lung adenocarcinoma with distinctive clinicopathological features (21). MIA is a very common type of stage I lung cancer and its prognosis remains controversial. The present study retrospectively detected EGFR mutations in patients with MIA from a Chinese population and evaluated the association between the mutation status and clinicopathological characteristics. The results indicated that lung MIA occurred more frequently in females, patients who had never smoked, patients aged 51-60 years and patients with a single tumor in the right lung. The results of the present study revealed the clinical characteristics of MIA in a relatively large cohort. Previous studies have suggested that EGFR mutations are more frequently observed (40-60\%) in lung adenocarcinomas of Asian patients (22-26). It has been revealed that the EGFR mutations are significantly associated with MIA and more frequently detected in Japanese patients with MIA $(14,15)$. To the best of our knowledge, the present study was the first to evaluate EGFR mutation status in a relatively large cohort of surgically resected lung MIAs from the Chinese population. The results indicated that the EGFR mutation rate was $75.95 \%$ in MIA, which was increased compared with the previously reported prevalence. The results of the present study also revealed that 19Del and L858R are the two dominant mutation subtypes, which was consistent with a previous report regarding patients with IA $(27,28)$. Additionally, a rare single mutation (exon $18 \mathrm{G} 719 \mathrm{X}$ ) and a rare concomitant mutation (exon $18 \mathrm{G} 719 \mathrm{X}$ and exon $20 \mathrm{~S} 768 \mathrm{I}$ ) were observed in the present cohort. According to the EGFR mutation features in the present study, it was concluded that MIA may harbor specific molecular characteristics, and further large-scale studies are required to confirm this.

EGFR is a member of the ErbB/HER family of transmembrane receptor tyrosine kinases expressed in several human malignancies, including lung cancer (29-31). EGFR-associated signaling pathways can be deregulated through different mechanisms, the most important of which is EGFR mutation (32). The most common EGFR mutations are 19Del and L858R, which are known as activating EGFR mutations in NSCLC (33). Activating EGFR mutations may result in constitutive activation of the receptor and diverse downstream signaling pathways, independent of ligand binding $(34,35)$. The constitutive activation of EGFR-associated signaling pathways elicited by EGFR mutations are thought to be a significant contributor to the tumorigenesis of 
Table III. Association between the two subtypes of tyrosine kinase inhibitor-sensitive EGFR mutation and clinicopathological features.

\begin{tabular}{|c|c|c|c|c|c|}
\hline \multirow[b]{2}{*}{ Factor } & \multirow[b]{2}{*}{$\mathrm{n}$} & \multicolumn{4}{|c|}{ EGFR mutation status } \\
\hline & & 19Del & P-value & L858R & P-value \\
\hline Sex & & & 0.427 & & 0.310 \\
\hline Male & 32 & $13(40.63)$ & & $10(31.25)$ & \\
\hline Female & 47 & $15(31.91)$ & & $20(42.55)$ & \\
\hline Age & & & 0.062 & & 0.902 \\
\hline$\leq 50$ & 16 & $8(50.00)$ & & $5(31.25)$ & \\
\hline $51-60$ & 31 & $14(45.16)$ & & $12(38.71)$ & \\
\hline $61-70$ & 21 & $5(23.81)$ & & $8(38.10)$ & \\
\hline$>70$ & 11 & $1(9.09)$ & & $5(45.45)$ & \\
\hline Smoking status & & & 0.515 & & 0.977 \\
\hline Smoked & 8 & $2(25.00)$ & & $3(37.50)$ & \\
\hline Never smoked & 71 & $26(36.62)$ & & $27(38.03)$ & \\
\hline Presence of GGO & & & 0.096 & & 0.263 \\
\hline Presence & 73 & $24(32.88)$ & & $29(39.73)$ & \\
\hline Absence & 6 & $4(66.66)$ & & $1(16.67)$ & \\
\hline Tumor number & & & 0.227 & & 0.678 \\
\hline Single & 65 & $25(38.46)$ & & $24(36.92)$ & \\
\hline Multiple & 14 & $3(21.43)$ & & $6(42.86)$ & \\
\hline Tumor site & & & 0.343 & & 0.533 \\
\hline Left & 28 & $7(25.00)$ & & $11(39.29)$ & \\
\hline Right & 49 & $20(40.82)$ & & $19(38.78)$ & \\
\hline Bilateral & 2 & $1(50.00)$ & & $0(0.00)$ & \\
\hline Tumor size, $\mathrm{cm}$ & & & $0.007^{\mathrm{a}}$ & & $<0.0001^{\mathrm{a}}$ \\
\hline$\leq 1$ & 46 & $22(47.83)$ & & $9(19.57)$ & \\
\hline$>1, \leq 2$ & 33 & $6(18.18)$ & & $21(63.64)$ & \\
\hline Maximum diameter of tumor microinvasion, $\mathrm{mm}$ & & & $0.019^{\mathrm{b}}$ & & $0.001^{\mathrm{a}}$ \\
\hline$\leq 2$ & 34 & $17(50.00)$ & & $6(17.65)$ & \\
\hline$>2, \leq 5$ & 45 & $11(24.44)$ & & $24(53.33)$ & \\
\hline Histological sub-type of microinvasion component & & & 0.112 & & 0.084 \\
\hline Lepidic predominant & 43 & $19(44.19)$ & & $14(32.56)$ & \\
\hline Acinar predominant & 32 & $9(28.13)$ & & $16(50.00)$ & \\
\hline Other subtype & 4 & $0(0.00)$ & & $0(0.00)$ & \\
\hline Intratumoral fibrosis & & & $0.011^{\mathrm{b}}$ & & $<0.0001^{\mathrm{a}}$ \\
\hline Presence & 46 & $11(23.91)$ & & $27(58.69)$ & \\
\hline Absence & 33 & $17(51.52)$ & & $3(9.09)$ & \\
\hline Intratumoral inflammatory cells infiltration & & & $0.002^{\mathrm{a}}$ & & $<0.0001^{\mathrm{a}}$ \\
\hline Presence & 38 & $7(18.42)$ & & $25(65.79)$ & \\
\hline Absence & 41 & $21(51.22)$ & & $5(12.20)$ & \\
\hline Percentage of lymphocytes in peripheral blood & & & 0.686 & & 0.510 \\
\hline$\leq 30$ & 19 & $6(31.58)$ & & $6(31.58)$ & \\
\hline$>30$ & 60 & $22(36.67)$ & & $24(40.00)$ & \\
\hline TTF-1 & & & 0.847 & & $0.030^{\mathrm{b}}$ \\
\hline Positive & 63 & $22(34.92)$ & & $29(46.03)$ & \\
\hline Negative & 16 & $6(37.50)$ & & $1(6.25)$ & \\
\hline
\end{tabular}

${ }^{\mathrm{a}} \mathrm{P}<0.01$ and ${ }^{\mathrm{b}} \mathrm{P}<0.05$. EGFR, epidermal growth factor receptor; GGO, ground glass opacity; TTF-1, thyroid transcription factor 1 ; other histopathological subtypes, including papillary predominant, micropapillary predominant and solid pattern predominant classified and recorded according to the new IASLC/ATS/ERS lung adenocarcinoma classification; median percentage of lymphocytes in peripheral blood was 30\%; therefore, all enrolled patients were divided into two subgroups. 


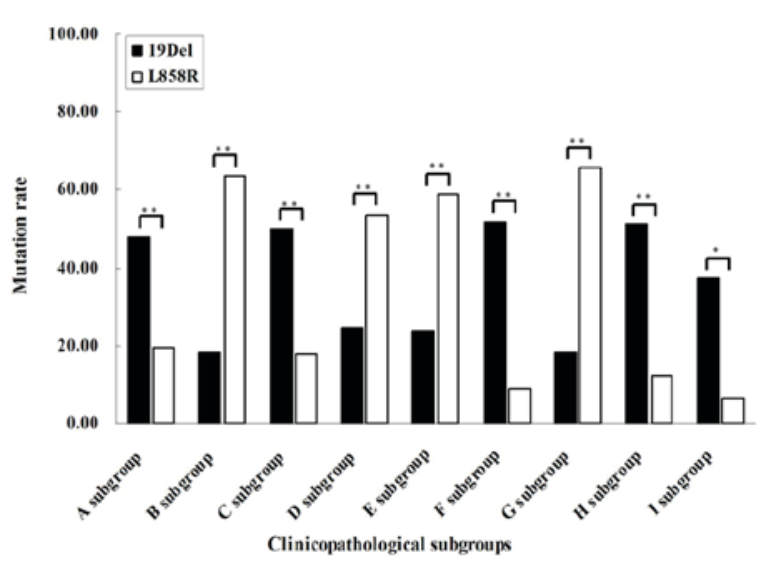

Figure 3. Comparison of clinicopathological characteristics between the 19Del and L858R status for various subgroups. (A-I) The X-axis indicates various subgroups defined as different clinicopathological features and the $y$-axis indicates the epidermal growth factor receptor mutation rate. A subgroup indicates tumor size $\leq 1 \mathrm{~cm}, \mathrm{P}=0.004$; B subgroup indicates $1 \mathrm{~cm}<$ tumor size $\leq 2 \mathrm{~cm}, \mathrm{P}=0.000 ; \mathrm{C}$ subgroup indicates maximum diameter of tumor microinvasion $\leq 2 \mathrm{~mm}, \mathrm{P}=0.005$; D subgroup indicates $2 \mathrm{~mm}<$ maximum diameter of tumor microinvasion $\leq 5 \mathrm{~mm}, \mathrm{P}=0.005$; E subgroup indicates the presence of intratumoral fibrosis, $\mathrm{P}=0.001$; $\mathrm{F}$ subgroup indicates the absence of intratumoral fibrosis, $\mathrm{P}=0.000 ; \mathrm{G}$ subgroup indicates the presence of intratumoral inflammatory cell infiltration, $\mathrm{P}=0.000 ; \mathrm{H}$ subgroup indicates the absence of intratumoral inflammatory cell infiltration, $\mathrm{P}=0.000$ and I subgroup indicates negative thyroid transcription factor-1 protein expression, $\mathrm{P}=0.033$. ${ }^{*} \mathrm{P}<0.05$ and ${ }^{* *} \mathrm{P}<0.01$ 19Del subgroup compared with the L858R subgroup.

NSCLC. Numerous TKIs have been developed to inhibit EGFR-sensitizing mutations for the molecular-targeted therapy of NSCLC $(36,37)$. EGFR mutations may be predictive biomarkers of EGFR TKI responsiveness (38-43). Previous studies have focused on investigating the applications of EGFR TKIs in early resectable NSCLC, and several research groups have concluded its feasibility and safety (44-47). A number of ongoing studies have aimed to provide further evidence for guiding the extended application of targeted therapy for advanced and early stage lung cancer. Therefore, a complete understanding of EGFR mutation features and the potential clinical significance in MIA may provide additional information regarding the clinical management of early-stage lung cancer. However, due to the small tumor size in patients with MIA, the quantity and quality of tumor samples is not always sufficient for the purpose of mutation analysis in clinical practice. It would be beneficial to identify efficient alternative indicators of EGFR mutation status prior to testing. Therefore, the present study evaluated the association between the EGFR mutation and various clinicopathological features in MIA (Table II). Analysis of the unselected group of patients suggested no association between the EGFR mutation and sex, age at diagnosis, smoking history, or tumor site/size/number in the 79 patients with MIA. With respect to IA, previous reports have demonstrated that EGFR mutations are commonly observed in females and patients who have never smoked $(48,49)$. The results of the present study for MIA were not consistent with those of previous studies of IA. However, a study by Lai et al (28) also revealed that there was no significant association between EGFR mutation subtype and sex, smoking history or tumor histology in IA. The discrepancy may be caused by the intrinsic molecular characteristics of MIA or could be explained by variations between selected and unselected tumor stages or sampling error. Further studies are required to shed light on these discrepancies and their underlying causes. On the other hand, the results of the present study suggested that EGFR mutations were more frequently observed in lepidic and acinar predominant microinvasive component subtypes of MIA, which was consistent with the previously obtained results for IA $(44,50)$.

In addition, the results of the present study indicated that EGFR mutations were significantly associated with TTF-1 expression in MIA. Previous studies have suggested a significant association between EGFR mutation and TTF-1 protein expression in advanced lung adenocarcinoma (51-53), particularly for exon 21 mutations (54). It was concluded that TTF-1 may be regarded not only as a significant marker for the diagnosis of lung adenocarcinoma, but also as useful guidance regarding EGFR mutation status prior to molecular testing. Furthermore, previous data revealed the potential interaction signal between TTF-1 and EGFR in lung adenocarcinoma (55). It can be hypothesized that the interactivity between TTF-1 expression and EGFR mutation may serve key roles in the initiation of lung adenocarcinoma. Therefore, further studies are required to investigate this interaction in lung adenocarcinoma, particularly in early stage tumors. With respect to the expression of TTF-1 in MIA, the present study identified 16 patients with MIA who were TTF-1-negative (Fig. 2). Previous studies had reported several TTF-1-negative patients with MIA in their cohorts $(18,56)$. The exact expression profile of TTF-1 and the associated significance requires further investigation in patients with MIA. The results of the present study suggested that the EGFR mutation occurred more frequently in patients with MIA with intratumoral fibrosis and inflammatory cell infiltration. To the best of our knowledge, the association between these two pathological features and the EGFR mutation status has not been previously revealed.

The present study concluded that intratumoral fibrosis and inflammatory cell infiltration could be regarded as alternative indicators for the identification of EGFR mutations in patients with MIA, or even IA. Previous studies have also indicated that tumor cell proliferation and invasiveness could be affected by alterations in the tumor microenvironment, including intratumoral fibrosis and inflammatory cell infiltration $(57,58)$. Based on the results of the present study, we hypothesize an association between the clinical outcome of MIA and EGFR mutation status. Further studies are required to validate this hypothesis.

The present study conducted subgroup analysis (Table III), which suggested that 19Del and L858R mutations were associated with pathological features, including tumor size, diameter of tumor microinvasion, intratumoral fibrosis and inflammatory cell infiltration. The differential results between the group and subgroup analyses suggested that lung MIA harboring different EGFR mutation subtypes may exhibit distinctive clinicopathological characteristics. In addition, the results of the present study suggested that TTF- $1 \mathrm{w}$ expressionwwaswwsignificantlyw associated with the L858R mutation, but not with the 19Del mutation. Taken together, the present study indicated that it is meaningful to consider MIA 


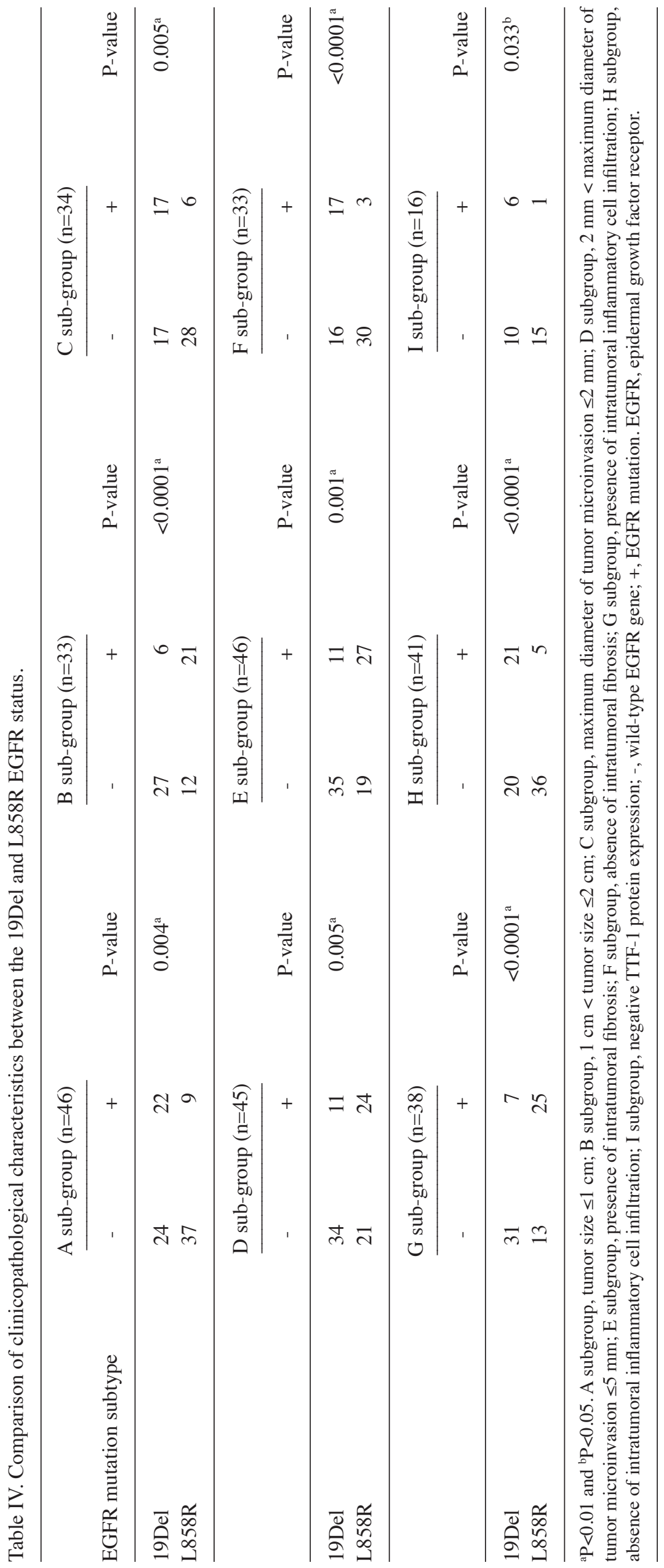


as a group of different subsets based on the EGFR mutation subtype.

The present study subsequently conducted a stratification analysis regarding the association of 19Del and L858R, respectively with certain clinicopathological features (Fig. 3; Table IV). The present data indicated that the 19Del mutation was more frequently detected in MIA with the following features: Smaller tumor size, smaller area of microinvasion, no intratumoral fibrosis, inflammatory cell infiltration and TTF-1 expression. By contrast, the L858R mutation is more frequently observed in MIA with entirely different characteristics compared with 19Del, including larger tumor size, larger area of microinvasion, presence of intratumoral fibrosis and inflammatory cell infiltration. Previous studies have consistently demonstrated that 19Del and L858R mutations show different prognostic and predictive roles in IA $(5,59)$. Data from these studies suggested that lung IA harboring 19Del and L858R should be regarded as different diseases. However, there have been no studies evaluating the differences between the 19Del and L858R subgroups in surgically resected MIA. The present results revealed that there were significant differences in tumor microenvironment-associated histological characteristics, including intratumoral fibrosis and inflammatory cell infiltration, between MIA cases with 19Del and L858R mutations. Previous studies proposed that these two histological characteristics could be considered as prognostic markers for a number of tumor types $(57,58)$. Considering these data, it can be hypothesized that clinical outcomes of MIA may be affected by EGFR mutation subtype. The prognosis of MIA remains unclear (60). It has been reported that EGFR mutation status has no effect on the prognosis of patients with early stage lung adenocarcinoma (61). However, the present data provide preliminary evidence to support consideration of EGFR mutation status as indication of prognostic stratification in future clinical studies involving MIA. Follow-up data are being collected and outcome analysis will be investigated in our future work. Furthermore, an increased number of MIA cases will also be included the future studies.

In conclusion, to the best of our knowledge, the present study was the first to reveal that surgically resected MIA tissues with different EGFR gene statuses exhibit distinct clinicopathological features. The results further suggest that there were significant differences in tumor microenvironment-associated histological characteristics between MIA with 19Del and L858R. Therefore, the present study concluded that the clinical outcomes of MIA may be affected by EGFR mutation subtypes and that EGFR mutation analysis should be considered for prognostic evaluation and clinical management of MIA.

\section{Acknowledgements}

The authors would like to thank Dr Bo Meng and Dr Jingjing Chen (Department of Pathology, Anhui Provincial Hospital) for providing technical assistance.

\section{Funding}

The present study was supported by grants from the National Natural Science Foundation of China (grant no. 81602605).

\section{Availability of data and materials}

The datasets used and/or analyzed during the current study are available from the corresponding author on reasonable request.

\section{Authors' contributions}

ML conceived and designed the experiments. ML and MLZ performed the experiments. LK, CYL and MC analyzed the data. ML, LK and MC contributed reagents/materials/analysis tools. ML, CYL and MLZ performed clinicopathological assessment. ML and CYL wrote the manuscript. The final version of the manuscript was read and approved by all authors.

\section{Ethics approval and consent to participate}

The present study was approved by the Institutional Review Board of Anhui Provincial Hospital, The First Affiliated Hospital of University of Science and Technology of China (reference no. 20160183), and written informed consent was obtained from all participants.

\section{Patient consent for publication}

Written informed consent for the publication of the clinical details was obtained from the patient.

\section{Competing interests}

The authors declare that they have no competing interests.

\section{References}

1. Siegel RL, Miller KD and Jemal A: Cancer statistics. CA Cancer J Clin 67: 7-30, 2017.

2. She J, Yang P, Hong Q and Bai C: Lung cancer in China: Challenges and interventions. Chest 143: 1117-1126, 2013.

3. Travis WD, Brambilla E, Nicholson AG, Yatabe Y, Austin JHM, Beasley MB, Chirieac LR, Dacic S, Duhig E, Flieder DB, et al: The 2015 world health organization classification of lung tumors: Impact of genetic, clinical and radiologic advances since the 2004 classification. J Thorac Oncol 10: 1243-1260, 2015.

4. Lemjabbar-Alaoui H, Hassan OU, Yang YW and Buchanan P: Lung cancer: Biology and treatment options. Biochim Biophys Acta 1856: 189-210, 2015

5. Rosell R, Moran T, Queralt C, Porta R, Cardenal F, Camps C, Majem M, Lopez-Vivanco G, Isla D, Provencio M, et al: Screening for epidermal growth factor receptor mutations in lung cancer. N Engl J Med 361: 958-967, 2009.

6. Huang SF, Liu HP, Li LH, Ku YC, Fu YN, Tsai HY, Chen YT, Lin YF, Chang WC, Kuo HP, et al: High frequency of epidermal growth factor receptor mutations with complex patterns in non-small cell lung cancers related to gefitinib responsiveness in Taiwan. Clin Cancer Res 10: 8195-8203, 2004.

7. Pao W and Miller VA: Epidermal growth factor receptor mutations, small-molecule kinase inhibitors, and non-small-cell lung cancer: Current knowledge and future directions. J Clin Oncol 23: 2556-2568, 2005.

8. Giaccone G and Rodriguez JA: EGFR inhibitors: What have we learned from the treatment of lung cancer? Nat Clin Pract Oncol 2: 554-561, 2005

9. Wu YL, Zhou C, Hu CP, Feng J, Lu S, Huang Y, Li W, Hou M, Shi JH, Lee KY, et al: Afatinib versus cisplatin plus gemcitabine for first-line treatment of Asian patients with advanced non-small-cell lung cancer harbouring EGFR mutations (LUXLung 6): An open-label, randomised phase 3 trial. Lancet Oncol 15: 213-222, 2014. 
10. Sequist LV, Yang JC, Yamamoto N, O'Byrne K, Hirsh V, Mok T, Geater SL, Orlov S, Tsai CM, Boyer M, et al: Phase III study of afatinib or cisplatin plus pemetrexed in patients with metastatic lung adenocarcinoma with EGFR mutations. J Clin Oncol 31: 3327-3334, 2013.

11. Inoue A, Kobayashi K, Maemondo M, Suqawara S, Oizumi S, Isobe H, Gemma A, Harada M, Yoshizawa H, Kinoshita I, et al: Updated overall survival results from a randomized phase III trial comparing gefitinib with carboplatin-paclitaxel for chemo-naïve non-small cell lung cancer with sensitive EGFR gene mutations (NEJ002). Ann Oncol 24: 54-59, 2013.

12. Mitsudomi T, Morita S, Yatabe Y, Negoro S, Okamoto I, Tsurutani J, Seto T, Satouchi M, Tada H, Hirashima T, et al: Gefitinib versus cisplatin plus docetaxel in patients with non-small cell lung cancer harboring mutations of the epidermal growth factor receptor (WJTOG3405): An open label, randomised phase 3 trial. Lancet Oncol 11: 121-128, 2010.

13. Zhao W, Wang H, Xie J and Tian B: A clinicopathological study of small lung adenocarcinoma $1 \mathrm{~cm}$ or less in size: Emphasis on histological subtypes associated with lymph node metastasis and recurrence. Int J Surg Pathol 26: 4-11, 2018.

14. Yoshizawa A, Sumiyoshi S, Sonobe M, Kobayashi M, Fujimoto M, Kawakami F, Tsuruyama T, Travis WD, Date H and Haga H: Validation of the IASLC/ATS/ERS lung adenocarcinoma classification for prognosis and association with EGFR and KRAS gene mutations: Analysis of 440 Japanese patients. J Thorac Oncol 8: 52-61, 2013.

15. Yanagawa N, Shiono S, Abiko M, Ogata SY, Sato T and Tamura G: The correlation of the international association for the study of lung cancer (IASLC)/American thoracic society (ATS)/European respiratory society (ERS) classification with prognosis and EGFR mutation in lung adenocarcinoma. Ann Thorac Surg 98: 453-458, 2014.

16. Travis WD, Brambilla E, Burke AP, Marx A and Nicholson AG: WHO classification of tumors of lung, pleural, thymus and heart. J Thorac Oncol 10: 1240-1242, 2015.

17. Travis WD, Brambilla E, Noguchi M, Nicholson AG, Geisinger K, Yatabe Y, Powell CA, Beer D, Riely G, Garg K, et al: International association for the study of lung cancer/American thoracic society/European respiratory society: International multidisciplinary classification of lung adenocarcinoma: Executive summary. Proc Am Thorac Soc 8: 381-385, 2011.

18. Zhou C, Zhao J, Shao J and Li W: Prognostic relevance of TTF-1 expression in stage I adenocarcinoma. Oncotarget 8: 107462-107468, 2017.

19. Kadota K, Nitadori J, Sarkaria IS, Sima CS, Jia X, Yoshizawa A, Rusch VW, Travis WD and Adusumilli PS: Thyroid transcription factor-1 expression is an independent predictor of recurrence and correlates with the IASLC/ATS/ERS histologic classification in patients with stage I lung adenocarcinoma. Cancer 119: 931-938, 2013.

20. Barletta JA, Perner S, Iafrate AJ, Yeap BY, Weir BA, Johnson LA, Johnson BE, Meyerson M, Rubin MA, Travis WD, et al: Clinical significance of TTF-1 protein expression and TTF-1 gene amplification in lung adenocarcinoma. J Cell Mol Med 13: 1977-1986, 2009.

21. Travis WD, Brambilla E, Noguchi M, Nicholson AG, Geisinger K, Yatabe Y, Powell CA, Beer D, Riely G, Garg K, et al: International association for the study of lung cancer/American thoracic society/European respiratory society international multidisciplinary classificatiosn of lung adenocarcinoma. J Thorac Oncol 6: 244-285, 2011.

22. Shigematsu H, Lin L, Takahashi T, Nomura M, Suzuki M, Wistuba II, Fong KM, Lee H, Toyooka S, Shimizu N, et al: Clinical and biological features associated with epidermal growth factor receptor gene mutations in lung cancers. J Natl Cancer Inst 97: 339-346, 2005.

23. Fridlender ZG, Sun J, Kim S, Kapoor V, Cheng G, Ling L, Worthen GS and Albelda SM: Polarization of tumor-associated neutrophil phenotype by TGF-beta: 'N1' versus 'N2' TAN. Cancer Cell 16: 183-194, 2009.

24. Cedres S, Torrejon D, Martinez A, Martinez P, Navarro A, Zamora E, Mulet-Margalef N and Felip E: Neutrophil to lymphocyte ratio (NLR) as an indicator of poor prognosis in stage IV non-small cell lung cancer. Clin Transl Oncol 14: 864-869, 2012

25. D'Angelo SP, Janjiqian YY, Ahye N, Riely GJ, Chaft JE, Sima CS, Shen R, Zheng J, Dycoco J, Kris MG, et al: Distinct clinical course of EGFR-mutant resected lung cancers: Results of testing of 1118 surgical specimens and effects of adjuvant gefitinib and erlotinib. J Thorac Oncol 7: 1815-1822, 2012.
26. Yoshizawa A, Motoi N, Riely GJ, Sima CS, Gerald WL, Kris MG, Park BJ, Rusch VW and Travis WD: Impact of proposed IASLC/ATS/ERS classification of lung adenocarcinoma: Prognostic subgroups and implications for further revision of staging based on analysis of 514 stage I cases. Mod Pathol 24: 653-664, 2011.

27. Ning H, Liu M, Wang L, Yang Y, Song N, Xu X, Ju J and Jiang G: Clinicopathological features of Chinese lung cancer patients with epidermal growth factor receptor mutation. J Thorac Dis 9: 796-801, 2017.

28. Lai Y, Zhang Z, Li J, Sun D, Zhou Y, Jiang T, Han Y, Huang L, Zhu Y, Li X and Yan X: EGFR mutations in surgically resected fresh specimens from 697 consecutive Chinese patients with non-small cell lung cancer and their relationships with clinical features. Int J Mol Sci 14: 24549-24559, 2013.

29. Mendelsohn J and Baselga J: Epidermal growth factor receptor targeting in cancer. Semin Oncol 33: 369-385, 2006

30. Ciardiello F and Tortora G: EGFR antagonists in cancer treatment. N Engl J Med 358: 1160-1174, 2008.

31. Thakur MK and Gadgeel SM: Predictive and prognostic biomarkers in non-small cell lung cancer. Semin Respir Crit Care Med 37: 760-770, 2016.

32. Gazdar AF and Minna JD: Deregulated EGFR signaling during lung cancer progression: Mutations, amplicons, and autocrine loops. Cancer Prev Res (Phila) 1: 156-160, 2008.

33. Shroff GS, de Groot PM, Papadimitrakopoulou VA, Truong MT and Carter BW: Targeted therapy and immunotherapy in the treatment of non-small cell lung cancer. Radiol Clin North Am 56: 485-495, 2018.

34. Ciuffreda L, Incani UC, Steelman LS, Abrams SL, Falcone I, Curatolo AD, Chappell WH, Franklin RA, Vari S, Cognetti F, et al: Signaling intermediates (MAPK and PI3K) as therapeutic targets in NSCLC. Curr Pharm Des 20: 3944-3957, 2014.

35. Luo J, Solimini NL and Elledge SJ: Principles of cancer therapy: Oncogene and non-oncogene addiction. Cell 136: 823-837, 2009.

36. Cooper WA, O'toole S, Boyer M, Horvath L and Mahar A: What's new in non-small cell lung cancer for pathologists: The importance of accurate subtyping, EGFR mutations and ALK rearrangements. Pathology 43: 103-115, 2011.

37. Gadgeel SM, Ramalingam SS and Kalemkerian GP: Treatment of lung cancer. Radiol Clin North Am 50: 961-974, 2012.

38. Wu YL, Zhou C, Liam CK, Wu G, Liu X, Zhong Z, Lu S, Cheng Y, Han B, Chen L, et al: First-line erlotinib versus gemcitabine/cisplatin in patients with advanced EGFR mutation-positive non-small-cell lung cancer: Analyses from the phase III, randomized, open-label, ENSURE study. Ann Oncol 26: 1883-1889, 2015.

39. Rosell R, Carcereny E, Gervais R, Vergnenegre A, Massuti B, Felip E, Palmero R, Garcia-Gomez R, Pallares C, Sanchez JM, et al: Erlotinib versus standard chemotherapy as first-line treatment for European patients with advanced EGFR mutation-positive non-small-cell lung cancer (EURTAC): A multicentre, open-label, randomised phase 3 trial. Lancet Oncol 13: 239-246, 2012.

40. Zhou C, Wu YL, Chen G, Feng J, Liu XQ, Wang C, Zhang S, Wang J, Zhou S, Ren S, et al: Erlotinib versus chemotherapy as first-line treatment for patients with advanced EGFR mutation-positive non-small-cell lungcancer (OPTIMAL, CTONG-0802): A multicentre, open-label, randomised, phase 3 study. Lancet Oncol 12: 735-742, 2011.

41. Han JY, Park K, Kim SW, Lee DH, Kim HY, Kim HT, Ahn MJ, Yun T, Ahn JS, Suh C, et al: First-SIGNAL: First-line single-agent iressa versus gemcitabine and cisplatin trial in never-smokers with adenocarcinoma of the lung. J Clin Oncol 30: 1122-1128, 2012.

42. Boolell V, Alamgeer M, Watkins DN and Ganju V: The evolution of therapies in non-small cell lung cancer. Cancers (Basel) 7: 1815-1846, 2015.

43. Ryska A, Dziadziuszko R, Olszewski W, Berzinec P, Oz B, Gottfried M, Cufer T, Samarzija M, Plank L, Ostoros G and Timar J: Molecular diagnostics of lung cancer. Magy Onkol 59: 259-266, 2015

44. Janjigian YY, Park BJ, Zakowski MF, Ladanyi M, Pao W, D'Angelo SP, Kris MG, Shen R, Zheng J and Azzoli CG: Impact on disease-free survival of adjuvant erlotinib or gefitinib in patients with resected lung adenocarcinomas that harbor EGFR mutations. J Thorac Oncol 6: 569-575, 2011.

45. Wang Q, Wang H, Li P, Zhu H, He C, Wei B, Ma J and Ma Z: Erlotinib-based perioperative adjuvant therapy for a case of unresectable stage IIIA (N2) nonsmall cell lung cancer. Am J Med Sci 340: 321-325, 2010. 
46. Lara-Guerra H, Chung CT, Schwock J, Pintilie M, Hwang DM, Leighl NB, Waddell TK and Tsao MS: Histopathological and immunohistochemical features associated with clinical response to neoadjuvant gefitinib therapy in early stage non-small cell lung cancer. Lung Cancer 76: 235-241, 2012.

47. Schaake EE, Kappers I, Codrington HE, Valdes Olmos RA, Teertstra HJ, van Pel R, Burgers JA, van Tinteren $H$ and Klomp HM: Tumor response and toxicity of neoadjuvant erlotinib in patients with early-stage non-small-cell lung cancer. J Clin Oncol 30: 2731-2738, 2012.

48. Tokumo M, Toyooka S, Kiura K, Shigematsu H, Tomii K, Aoe M, Ichimura K, Tsuda T, Yano M, Tsukuda K, et al: The relationship between epidermal growth factor receptor mutations and clinicopathologic features in non-small cell lung cancers. Clin Cancer Res 11: 1167-1173, 2005.

49. Sonobe M, Manabe T, Wada H and Tanaka F: Mutations in the epidermal growth factor receptor gene are linked to smokingindependent, lung adenocarcinoma. Br J Cancer 93: 355-363, 2005.

50. Usuda K, Sagawa M, Motono N, Ueno M, Tanaka M, Machida Y, Matoba M, Taniguchi M, Tonami H, Ueda Y and Sakuma T: Relationships between EGFR mutation status of lung cancer and preoperative factors-Are they predictive? Asian Pac J Cancer Prev 15: 657-662, 2014.

51. Chung KP, Huang YT, Chang YL, Yu CJ, Yang CH, Chang YC, Shih JY and Yang PC: Clinical significance of thyroid transcription factor-1 in advanced lung adenocarcinoma under epidermal growth factor receptor tyrosine kinase inhibitor treatment. Chest 141: 420-428, 2012

52. Zhang Y, Wang R, Li Y, Pan Y, Hu H, Zhang Y, Li H, Shen L, $\mathrm{Yu}$ Y, Sun $Y$ and Chen H: Negative thyroid transcription factor 1 expression defines an unfavorable subgroup of lung adenocarcinomas. J Thorac Oncol 10: 1444-1450, 2015.

53. Sun PL, Seol H, Lee HJ, Yoo SB, Kim H, Xu X, Jheon S, Lee CT, Lee JS and Chung JH: High incidence of EGFR mutations in Korean men smokers with no intratumoral heterogeneity of lung adenocarcinomas: Correlation with histologic subtypes, EGFR/TTF-1 expressions, and clinical features. J Thorac Oncol 7: 323-330, 2012

54. Shanzhi W, Yiping H, Ling H, Jianming Z and Qiang L: The relationship between TTF-1 expression and EGFR mutations in lung adenocarcinomas. PLoS One 9: e95479, 2014.
55. Yamaguchi T, Yanagisawa K, Sugiyama R, Hosono $Y$, Shimada Y, Arima C, Kato S, Tomida S, Suzuki M, Osada H and Takahashi T: NKX2-1/ TITF1/ TTF-1-induced ROR1 is required to sustain EGFR survival signaling in lung adenocarcinoma. Cancer Cell 21: 348-361, 2012.

56. Huang TW, Lin KF, Lee CH, Chang H, Lee SC and Shieh YS: The role of thyroid transcription factor-1 and tumor differentiation in resected lung adenocarcinoma. Sci Rep 7: 14222, 2017.

57. Lee HO, Mullins SR, Franco-Barraza J, Valianou M, Cukierman E and Cheng JD: FAP-overexpressing fibroblasts produce an extracellular matrix that enhances invasive velocity and directionality of pancreatic cancer cells. BMC Cancer 11: 245, 2011.

58. Brambilla E, Le Teuff G, Marguet S, Lantuejoul S, Dunant A, Graziano S, Pirker R, Douillard JY, Le Chevalier T, Filipits M, et al: Prognostic effect of tumor lymphocytic infiltration in resectable non-small-cell lung cancer. J Clin Oncol 34: 1223-1230, 2016

59. Yang JC, Wu YL, Schuler M, Sebastian M, Popat S, Yamamoto N, Zhou $\mathrm{C}, \mathrm{Hu} \mathrm{CP}, \mathrm{O}$ Byrne K, Feng J, et al: Afatinib versus cisplatin-based chemotherapy for EGFR mutation-positive lung adenocarcinoma (LUX-Lung 3 and LUX-Lung 6): Analysis of overall survival data from two randomized, phase 3 trials. Lancet Oncol 16: 141-151, 2015.

60. Kadota K, Villena-Vargas J, Yoshizawa A, Motoi N, Sima CS Riely GJ, Rusch VW, Adusumilli PS and Travis WD: Prognostic significance of adenocarcinoma in situ, minimally invasive adenocarcinoma, and nonmucinous lepidic predominant invasive adenocarcinoma of the lung in patients with stage I disease. Am J Surg Pathol 38: 448-460, 2014.

61. Kaseda K, Asakura K, Kazama A and Ozawa Y Clinicopathological and prognostic features of surgically resected pathological stage I lung adenocarcinoma harboring epidermal growth factor receptor and K-ras mutation. Thorac Cancer 8: 229-237, 2017.

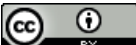

This work is licensed under a Creative Commons Attribution 4.0 International (CC BY 4.0) License. 